\title{
Prediction of acute kidney injury within 30 days of cardiac surgery
}

\author{
Shu Yi Ng, MBBS, ${ }^{a}$ Masoumeh Sanagou, MSc, ${ }^{\text {b }}$ Rory Wolfe, $\mathrm{PhD},{ }^{\mathrm{b}}$ \\ Andrew Cochrane, MBBS, MPH, MEpid, FRACS, FRCS (CTh), ${ }^{\mathrm{a}}$ Julian A. Smith, MS, FRACS, ${ }^{a}$ and \\ Christopher Michael Reid, $\mathrm{PhD}^{\mathrm{b}}$
}

Objective: To predict acute kidney injury after cardiac surgery.

Methods: The study included 28,422 cardiac surgery patients who had had no preoperative renal dialysis from June 2001 to June 2009 in 18 hospitals. Logistic regression analyses were undertaken to identify the best combination of risk factors for predicting acute kidney injury. Two models were developed, one including the preoperative risk factors and another including the pre-, peri-, and early postoperative risk factors. The area under the receiver operating characteristic curve was calculated, using split-sample internal validation, to assess model discrimination.

Results: The incidence of acute kidney injury was 5.8\% (1642 patients). The mortality for patients who experienced acute kidney injury was $17.4 \%$ versus $1.6 \%$ for patients who did not. On validation, the area under the curve for the preoperative model was 0.77 , and the Hosmer-Lemeshow goodness-of-fit $P$ value was .06. For the postoperative model area under the curve was 0.81 and the Hosmer-Lemeshow $P$ value was .6. Both models had good discrimination and acceptable calibration.

Conclusions: Acute kidney injury after cardiac surgery can be predicted using preoperative risk factors alone or, with greater accuracy, using pre-, peri-, and early postoperative risk factors. The ability to identify high-risk individuals can be useful in preoperative patient management and for recruitment of appropriate patients to clinical trials. Prediction in the early stages of postoperative care can guide subsequent intensive care of patients and could also be the basis of a retrospective performance audit tool. (J Thorac Cardiovasc Surg 2014; $147: 1875-83$ )

\section{Supplemental material is available online.}

Earn CME credits at

http://jtcvs.com/cme/home

Postoperative renal dysfunction, also known as acute kidney injury (AKI), is a recognized and serious complication of cardiac surgery that increases in-hospital mortality, morbidity, length of stay, and hospital costs after surgery. ${ }^{1}$ Identifying patients who are at high risk of developing AKI after cardiac surgery will potentially enable improved

\footnotetext{
From the Department of Cardiothoracic Surgery, ${ }^{\mathrm{a}}$ Monash Medical Centre, and Department of Surgery, Monash University Faculty of Medicine, Nursing and Health Sciences, Melbourne, Australia; and Department of Epidemiology and Preventive Medicine, ${ }^{\mathrm{b}}$ Monash University Faculty of Medicine, Nursing and Health Sciences, Melbourne, Australia.

The Australasian Society of Cardiac and Thoracic Surgeons National Cardiac Surgery Database Program is funded by the Department of Health Victoria, and the Health Administration Corporation and the Clinical Excellence Commission, New South Wales.

Disclosures: Authors have nothing to disclose with regard to commercial support. Drs Ng and Sanagou are joint first authors.

Received for publication June 15, 2012; revisions received May 27, 2013; accepted for publication June 21, 2013; available ahead of print Aug 30, 2013.

Address for reprints: Masoumeh Sanagou, MSc, Department of Epidemiology and Preventive Medicine, Monash University Faculty of Medicine, Nursing and Health Sciences, Melbourne, Australia (E-mail: masoumeh.sanagou@monash.edu). $0022-5223 / \$ 36.00$

Copyright (c) 2014 by The American Association for Thoracic Surgery http://dx.doi.org/10.1016/j.jtcvs.2013.06.049
}

treatment decisions and support more informed patient education processes.

The incidence of AKI has varied, depending on the definition used, the postoperative period of the studies, and the specific population studied. Hence, it has been difficult to compare the results of published studies. Nevertheless, the incidence of postoperative AKI appears to range from $1 \%$ to $30 \%$, with in-hospital mortality varying from $14 \%$ to $60 \%{ }^{2-4}$ Postoperative renal replacement therapies (RRTs) are required for approximately $1 \%$ to $5 \%$ of cardiac surgery patients, ${ }^{5}$ with in-hospital mortality rates reportedly up to $70 \%$ in these patients. ${ }^{2,4}$

Several risk factors for postoperative AKI have been identified, including diabetes mellitus, congestive heart failure, intra-aortic balloon pump (IABP) use, preoperative serum creatinine, age, left main coronary stenosis, peripheral vascular disease, and cardiopulmonary bypass duration. ${ }^{3,5-7}$ Other possible risk factors for which the evidence has been less consistent include female gender, chronic obstructive pulmonary disease, infective endocarditis, emergent surgery, and crossclamp time..$^{2-4,6-10}$ Although some risk prediction tools have been proposed, they have included different combinations of risk factors, and a recent review found an absence of general agreement on the use of prediction models for AKI after cardiac surgery. ${ }^{11}$ Indeed, they concluded that additional studies are required to predict milder AKI not requiring dialysis.

From 2001, the Australian and New Zealand Society of Cardiac and Thoracic Surgeons (ANZSCTS) registry of 


\begin{tabular}{|c|c|}
\hline \\
\hline AKI & $\begin{array}{l}\text { Abbreviations and Acronyms } \\
\text { AKI = acute kidney iniury }\end{array}$ \\
\hline ANZSCT & $\begin{aligned}= & \text { Australian and New Zealand Society } \\
& \text { of Cardiac and Thoracic Surgeons }\end{aligned}$ \\
\hline AUC & $\begin{aligned}= & \text { area under the receiver operating } \\
& \text { characteristic curve }\end{aligned}$ \\
\hline BIC & $=$ Bayesian information criteria \\
\hline HL- $P$ & $=$ Hosmer-Lemeshow $P$ value \\
\hline IABP & $=$ intra-aortic balloon pump \\
\hline MSE & $=$ mean square error \\
\hline NYHA & $=$ New York Heart Association \\
\hline RBC & $=$ red blood cell \\
\hline RRT & $=$ renal replacement therapy \\
\hline
\end{tabular}

cardiac surgical procedures has collected outcomes, including complications after cardiac surgery, and collecting extensive patient, clinical, and surgical information. ${ }^{12}$ The aim of the present study was to use the ANZSCTS registry to identify the best combination of patient and surgical risk factors for predicting AKI as defined by either RRT or a substantially increased serum creatinine after cardiac surgery.

\section{METHODS}

\section{Study Population}

The ANZSCTS registry recorded data for 32,279 patients who had undergone cardiac surgery from 2001 to 2009 in 18 hospitals in Australia. The patient demographics and clinical and surgery variables were collected by the registry. ${ }^{12}$ From the existing data and the data availability in the registry, 38 pre-, peri-, and early postoperative variables potentially related to the development of AKI were chosen for consideration and are listed in Table 1 . The early postoperative variables were those for which the value would typically be known within 24 hours of surgery.

The potential risk factors, New York Heart Association (NYHA) class (2713 missing) and number of red blood cell (RBC) units (4241 missing), were not considered owing to the number of missing values. However, the use of RBCs (yes vs no) was considered.

Patients requiring preoperative renal dialysis $(\mathrm{n}=521)$ and those with missing data for postoperative renal function $(\mathrm{n}=86)$ and any of the variables listed in Table $1(\mathrm{n}=3250)$ were excluded. The data from the remaining 28,422 patients were used in the statistical analysis.

Three published models for predicting $\mathrm{AKI}^{13-15}$ were applied to the ANZSCTS registry data, and their performance was measured using the area under the receiver operating characteristic curve (AUC). Some variables in these models had different definitions in the ANZSCTS registry.

The present research project was undertaken after approval from the ANZSCTS Research Committee, which governs access to data from the registry. Ethical approval for the use of de-identified registry data for secondary research purposes, such as our project, had previously been provided by each participating institution's ethics review committee.

\section{Outcome Definition}

Development of AKI was defined by at least 2 of the following measures within 30 days after surgery: (1) increased serum creatinine to greater than $200 \mu \mathrm{mol} / \mathrm{L}(2.26 \mathrm{mg} / \mathrm{dL})$, (2) a doubling or greater increase in serum creatinine over the preoperative value, and (3) a new requirement for RRT.

\section{Statistical Analysis}

First, the data set was randomly divided in 2, forming a model creation data set ( $\mathrm{n}=17,095,60 \%$ of total patients) and a model validation data set $(\mathrm{n}=11,327)$. Next, 1000 bootstrap $^{16}$ samples (each 17,095 in size) were selected, with replacement from the model creation data set, and a logistic regression model for AKI incorporating all variables under consideration was applied to each of the 1000 samples. The number of times each candidate variable was significant $(P \leq .05)$ in the 1000 models was recorded.

The first candidate model included the risk factors significant in all 1000 bootstrap samples. Next, a sequence of other candidate models, each with 1 variable more than the previous, were identified as the remaining variables were added to the model in rank order according to the number of times they were significant in the 1000 bootstrap samples.

Using the creation data set, the AUC, ${ }^{17}$ Bayesian information criteria (BIC),${ }^{17}$ Hosmer-Lemeshow $P$ value (HL- $P$ ),${ }^{17}$ and prediction mean square error (MSE) ${ }^{17}$ were calculated for each of the candidate models. These 4 criteria were used to select a final model (the percentage of bootstrap samples in which an association was significant was not used for this purpose).

The prediction performance of the selected model was assessed by calculating the AUC, HL- $P$, and MSE using the validation data set. Finally, point scores proportional to the regression coefficient were assigned to the risk factors included in the final model. Next, for each patient, a risk score was calculated, and the average predicted risks for the different groups of patients are reported.

The statistical software package Stata, version 11 (StataCorp, College Station, Tex), was used for the present analysis.

\section{RESULTS}

A total of 32,279 cardiac operations were performed during the 8-year study period. The prevalence of AKI in the 3250 patients who were excluded because of missing data for pre-, peri-, and early postoperative variables was 5.8\% $(\mathrm{n}=189)$, not different from that for the included patients. In the 28,422 included patients, the mean age was 66 years, and $27 \%$ were women. AKI occurred in 1642 patients $(5.8 \%)$, and the 30-day mortality rate for patients who developed AKI was 17.4\% (compared with $1.6 \%$ for patients without $\mathrm{AKI}$ ). Table 1 includes an additional description of the pre-, peri-, and early postoperative characteristics for patients with and without AKI. From the data listed in Table 1, it can be seen that patients who developed postoperative AKI were slightly older and more often had diabetes, hypertension, peripheral vascular disease, respiratory disease, infective endocarditis, and previous myocardial infarction. More patients with postoperative AKI had congestive heart failure, arrhythmia, cardiogenic shock, the need for resuscitation and the use of inotropes on the day of surgery, or had undergone a previous cardiothoracic intervention (surgical or percutaneous). The bypass and crossclamp times were longer on the average in the group that developed AKI. IABP use and the use of RBCs were also more common in that group (Table 1).

All variables from the 3 published models, ${ }^{13-15}$ except for ejection fraction, race, and NYHA class, were among the variables considered for inclusion in the models we developed, although some variables had slightly different definitions. The ejection fraction was missing for $72 \%$ of the ANZSCTS patients. Two methods were used to 
TABLE 1. Demographic patient characteristics and pre-, peri-, and early postoperative data stratified by development of postoperative AKI

\begin{tabular}{|c|c|c|}
\hline Variable & $\begin{array}{c}\text { No AKI } \\
(n=26,780)\end{array}$ & $\begin{array}{c}\text { AKI } \\
(n=1642)\end{array}$ \\
\hline \multicolumn{3}{|l|}{ Patient characteristics } \\
\hline Men & 72.6 & 71.6 \\
\hline Age (y) & $66 \pm 12$ & $69 \pm 13$ \\
\hline Obesity $\left(\right.$ BMI $\left.>30 \mathrm{~kg} / \mathrm{m}^{2}\right)$ & 30.2 & 33.1 \\
\hline Diabetes & 27.4 & 36.5 \\
\hline Infective endocarditis & 1.6 & 5.7 \\
\hline Smoking history & 63.1 & 61.1 \\
\hline Current smoker & 13.1 & 9.2 \\
\hline \multicolumn{3}{|l|}{ Cardiac surgery procedure type } \\
\hline Isolated CABG & 64.4 & 42.3 \\
\hline Valve surgery only & 13.6 & 15.7 \\
\hline Valve and CABG & 10.2 & 17.7 \\
\hline Other* & 11.8 & 24.3 \\
\hline \multicolumn{3}{|l|}{$\begin{array}{l}\text { Preoperative serum creatinine level } \\
\qquad(\mu \mathrm{mol} / \mathrm{L})\end{array}$} \\
\hline$\leq 69$ & 9.7 & 3.6 \\
\hline $70-100$ & 63.7 & 41.8 \\
\hline $101-120$ & 14.4 & 19.2 \\
\hline $121-150$ & 6.9 & 17.4 \\
\hline$>150$ & 5.3 & 18.0 \\
\hline \multicolumn{3}{|l|}{ Urgency status } \\
\hline Elective & 63.4 & 51.4 \\
\hline Urgent & 32.4 & 34.2 \\
\hline Emergency & 3.8 & 12.4 \\
\hline Salvage & 0.3 & 2.1 \\
\hline \multicolumn{3}{|l|}{$\mathrm{eGFR}\left(\mathrm{mL} / \mathrm{min} / 1.73 \mathrm{~m}^{2}\right) \dagger$} \\
\hline$<30$ & 3.9 & 11.4 \\
\hline $30-60$ & 25.5 & 44.4 \\
\hline $60-90$ & 37.4 & 28.4 \\
\hline$\geq 90$ & 33.2 & 15.8 \\
\hline Congestive heart failure & 24.9 & 46.3 \\
\hline Cardiogenic shock & 1.7 & 9.6 \\
\hline Respiratory disease & 13.4 & 19.6 \\
\hline Arrhythmia & 14.0 & 26.9 \\
\hline Hypercholesterolemia & 70.2 & 65.3 \\
\hline Previous MI & 41.7 & 45.5 \\
\hline Hypertension & 71.3 & 76.7 \\
\hline $\begin{array}{l}\text { Cardiac catheterization (angiogram or } \\
\text { pressure study) }\end{array}$ & 94.3 & 88.9 \\
\hline \multicolumn{3}{|l|}{ Number of diseased coronary vessels } \\
\hline 0 & 20.1 & 28.9 \\
\hline 1 & 7.6 & 8.6 \\
\hline 2 & 19.0 & 15.0 \\
\hline 3 & 53.3 & 47.4 \\
\hline \multicolumn{3}{|l|}{ Left ventricular ejection fraction estimate } \\
\hline Normal $(>60 \%)$ & 51.5 & 40.9 \\
\hline Mild impairment (46\%-60\%) & 28.3 & 26.0 \\
\hline Moderate $(30 \%-45 \%)$ & 14.6 & 18.8 \\
\hline Severe $(<30 \%)$ & 5.6 & 14.3 \\
\hline Reoperative surgery & 7.8 & 14.6 \\
\hline Peripheral vascular disease & 10.8 & 16.8 \\
\hline CCS class & & \\
\hline
\end{tabular}

TABLE 1. Continued

\begin{tabular}{lcr}
\hline \multicolumn{1}{c}{ Variable } & $\begin{array}{c}\text { No AKI } \\
(\mathbf{n}=\mathbf{2 6 , 7 8 0})\end{array}$ & $\begin{array}{c}\text { AKI } \\
(\mathbf{n}=\mathbf{1 6 4 2})\end{array}$ \\
\hline No angina symptoms & 26.8 & 34.5 \\
$\quad$ Ordinary physical activity & 9.4 & 9.3 \\
$\quad$ Slight limitation of ordinary activity & 25.7 & 18.9 \\
$\quad$ Marked limitation of ordinary physical & 21.3 & 18.4 \\
$\quad$ activity & & \\
$\quad$ Inability to perform any physical & 16.8 & 18.9 \\
$\quad$ activity without discomfort & & \\
IABP use preoperatively & 2.8 & 8.2 \\
Previous cardiothoracic intervention & 17.9 & 24.1 \\
$\quad$ (surgical or percutaneous) & & \\
Critical preoperative state $\ddagger$ & 2.9 & 12.5 \\
Use of inotropes on day of surgery & 1.9 & 9.6 \\
Need for resuscitation (within 1 h & 0.7 & 3.8 \\
$\quad$ preoperatively) & & \\
Left main coronary stenosis & 18.2 & 17.5 \\
Immunosuppressive treatment & 2.1 & 3.5 \\
Peri- and early postoperative characteristics & & \\
Use of RBCs intra- or postoperatively & 40.6 & 77.0 \\
Reoperation for bleeding & 2.8 & 11.3 \\
Non-RBC products transfused intra- or & 23.7 & 52.0 \\
$\quad$ postoperatively & & \\
IABP use intra- or postoperatively & 2.1 & 12.3 \\
Bypass time >180 min & 7.5 & 24.0 \\
Crossclamp time (min) & & \\
$\quad<60$ & 32.1 & 23.5 \\
$\quad$ 60-120 & 54.8 & 49.5 \\
$\quad>120$ & 13.1 & 27.0 \\
Off-pump surgery & 5.1 & 2.9 \\
\hline D & & \\
\hline
\end{tabular}

Data presented as percentages or mean \pm standard deviation. $A K I$, Acute kidney injury; $B M I$, body mass index; $C A B G$, isolated coronary artery bypass grafting; $e G F R$, estimated glomerular filtration rate; $M I$, myocardial infarction; $C C S$, Canadian Cardiovascular Society (classification of angina); IABP, intra-aortic balloon pump; $R B C$, red blood cell. *Included aortic procedure, atrial arrhythmia surgery, correction of atrial septal defect, cardiac transplant, left ventricular aneurysm, cardiac tumor, pericardiectomy, left ventricular outflow tract myectomy for left ventricular outflow tract, correction of acquired ventricular septal defect, left ventricular reconstruction, cardiac trauma, left ventricle rupture repair, pulmonary thromboendarterectomy, other cardiac surgery, other noncardiac surgery, other congenital problems. †eGFR calculated using the Cockroft-Gault formula: for men: weight $(\mathrm{kg}) \times(140-$ age $[\mathrm{y}]) /(72 \times$ serum creatinine $[\mathrm{mg} / \mathrm{dL}])$; for women: weight $(\mathrm{kg}) \times(140-$ age [y] $\times 0.85 /(72 \times$ serum creatinine $[\mathrm{mg} / \mathrm{dL}])$. $\ddagger$ Included cardiogenic shock, need for resuscitation, and use of inotropes on day of surgery.

manage this variable. First, we restricted the analysis to those patients with complete data, and, second, we used an ejection fraction estimate, with selection of the closest cutoff to that used for the ejection fraction in each model. After restriction to those 2679 patients in the validation data set with complete data for all risk factors in the 3 models, an AUC of 0.61, 0.75, and 0.75 was found for the models reported by Mehta et al, ${ }^{14}$ Thakar et al, ${ }^{13}$ and Wijeysundera et $\mathrm{al},{ }^{15}$ respectively. The results when using the ejection fraction estimate $(n=9620)$ were similar to these results (corresponding AUC of $0.67,0.74$, and 0.74 ). For the model by Mehta et al, ${ }^{14}$ all patients were assumed to be in the respective reference categories for NYHA class and 
TABLE 2. Percentage of times each candidate variable was selected in 1000 bootstrap samples drawn from model creation data set

\begin{tabular}{|c|c|c|c|}
\hline \multicolumn{2}{|l|}{ Preoperative risk factor } & \multicolumn{2}{|l|}{ Pre-, peri-, early postoperative risk factor } \\
\hline Obesity & 100 & Obesity & 100 \\
\hline Infective endocarditis & 100 & Preoperative creatinine level & 100 \\
\hline Cardiac surgery procedure type & 100 & Diabetes & 100 \\
\hline Preoperative creatinine level & 100 & IABP use pre-, peri-, or postoperatively & 100 \\
\hline Diabetes & 99.9 & Infective endocarditis & 99.7 \\
\hline Urgency status & 97.8 & Bypass time & 98.8 \\
\hline Estimated glomerular filtration rate & 97.5 & Cardiogenic shock & 97.1 \\
\hline Congestive heart failure & 95.1 & Non-RBC blood products transfused intra- or postoperatively & 96.0 \\
\hline Age (per 10 y) & 94.7 & Gender & 94.1 \\
\hline Cardiogenic shock & 91.3 & Reoperation for bleeding & 95.6 \\
\hline Gender & 81.2 & Age (per 10 y) & 92.2 \\
\hline Respiratory disease & 76.9 & Estimated glomerular filtration rate & 88.3 \\
\hline Arrhythmia & 73.0 & Urgency status & 84.2 \\
\hline Hypercholesterolemia & 71.2 & Hypercholesterolemia & 81.8 \\
\hline Previous MI & 61.4 & Hypertension & 78.7 \\
\hline Hypertension & 59.9 & Cardiac surgery procedure type & 77.9 \\
\hline Cardiac catheterization (angiogram or pressure study) & 57.8 & Respiratory disease & 71.2 \\
\hline Number of diseased coronary vessels & 54.9 & Arrhythmia & 62.7 \\
\hline Ejection fraction estimate & 51.5 & Cardiac catheterization (angiogram or pressure study) & 62.6 \\
\hline Reoperative surgery & 27.7 & Congestive heart failure & 59.8 \\
\hline Peripheral vascular disease & 26.0 & Number of diseased coronary vessels & 59.1 \\
\hline CCS class & 23.3 & Previous MI & 54.2 \\
\hline IABP use preoperatively & 16.0 & Peripheral vascular disease & 32.5 \\
\hline Previous cardiothoracic intervention (surgical or percutaneous) & 13.4 & Critical preoperative state* & 24.1 \\
\hline Current smoker & 12.8 & CCS class & 15.6 \\
\hline Critical preoperative state* & 12.2 & Use of RBCs intra- or postoperatively & 13.6 \\
\hline Use of inotropes on day of surgery & 11.2 & Need for resuscitation (within $1 \mathrm{~h}$ preoperatively) & 8.0 \\
\hline Need for resuscitation (within $1 \mathrm{~h}$ preoperatively) & 6.8 & Crossclamp time & 7.9 \\
\hline Left main coronary stenosis & 6.8 & Previous cardiothoracic intervention (surgical or percutaneous) & 7.7 \\
\hline Immunosuppressive treatment & 5.2 & Ejection fraction estimate & 7.0 \\
\hline Smoking history & 4.7 & Current smoker & 7.0 \\
\hline & & Use of inotropes on day of surgery & 7.0 \\
\hline & & Immunosuppressive treatment & 6.9 \\
\hline & & Reoperative surgery & 5.3 \\
\hline & & Left main coronary stenosis & 4.5 \\
\hline & & Smoking history & 4.3 \\
\hline & & Off-pump surgery & 3.4 \\
\hline
\end{tabular}

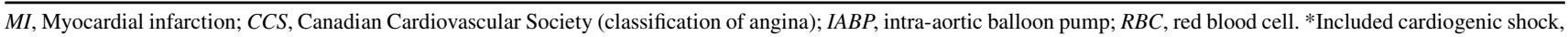
need for resuscitation, and use of inotropes on day of surgery.

race (with the reference category "white" for race capturing most ANZSCTS patients).

Patients assigned to the creation and validation data set were similar with respect to the pre-, peri-, and early postoperative characteristics (data not shown).

Using the creation data set, a total of 31 preoperative variables were included in the logistic regression model for postoperative AKI. The number of times each variable was significant in the 1000 bootstrap samples is listed in Table 2. The AUC, BIC, and MSE for each candidate model are reported in Figure 1.

Because of the desirability of minimizing the BIC and MSE and maximizing the AUC, the final preoperative model selected for predicting new AKI had 10 risk factors: obesity, infective endocarditis, cardiac surgery procedure type, preoperative creatinine level, diabetes, urgency status, estimated glomerular filtration rate, congestive heart failure, age, and cardiogenic shock (Table 3). The regression coefficients, odds ratios, and point scores ${ }^{18}$ for these risk factors are reported in Table 3 . These 10 risk factors were significant in $90 \%$ or more of the bootstrap samples.

The performance of the final preoperative model in the validation data set was as follows: $\mathrm{AUC}=0.77$, indicating good discrimination ability, and HL- $P=.06$, showing that calibration of the preoperative model was marginally acceptable.

The total point scores for all patients in the validation data set were divided into 3 groups: 4 to 15 points, 16 to 25 points, and 26 to 44 points. The corresponding mean predicted risk in the groups was $2 \%, 7 \%$, and $25 \%$ (information available online in Table E1). 


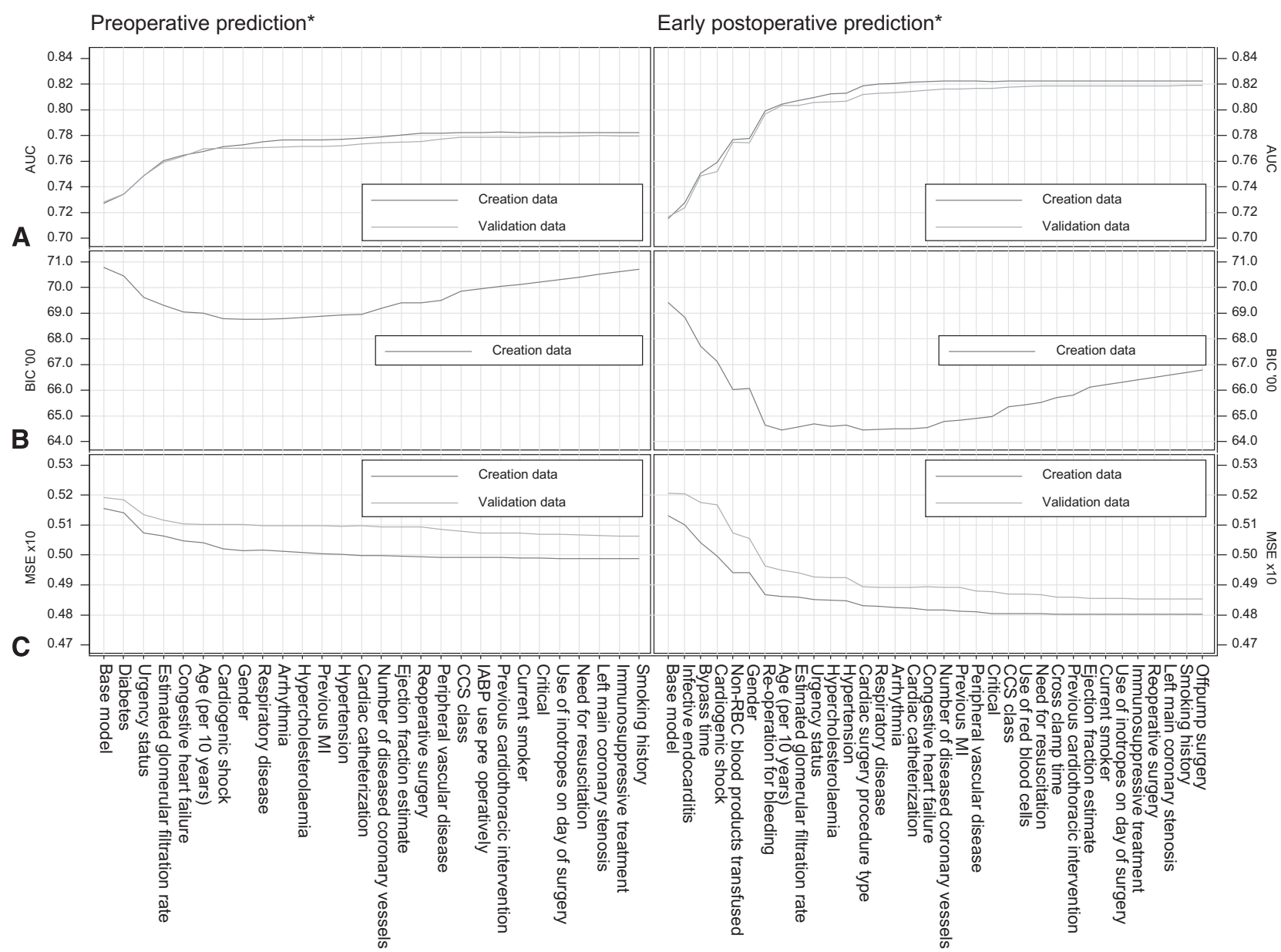

FIGURE 1. The area under the receiver operating characteristic curve (AUC) (A), Bayesian information criteria (BIC) (B), and mean square error (MSE) plots $(C)$ for increasingly complex models for the prediction of acute kidney injury (AKI) using up to 31 preoperative and 37 pre-, peri-, early postoperative risk factors in the model creation and validation data sets. Base model for preoperative model included obesity, infective endocarditis, cardiac surgery procedure type, and preoperative creatinine level identified as significant in all bootstrap samples. Base model for pre-, peri-, and early postoperative model included obesity, preoperative creatinine level, diabetes, intra-aortic balloon pump (IABP) use pre-, peri-, and/or postoperatively identified as significant in all bootstraps samples. MI, Myocardial infarction.

A total of 37 pre-, peri-, and early postoperative variables were included in the second logistic regression modeling process for postoperative AKI (IABP use preoperatively was combined with peri- or postoperative use to create a single 3-category variable for the present analysis). The results of 1000 bootstrap samples are listed in Table 2, and Figure 1 shows the AUCs, BICs, and MSEs in the models using the creation and validation data sets.

The final postoperative model selected for predicting new AKI had the 17 risk factors: obesity, preoperative creatinine level, diabetes, IABP use pre-, peri-, and/or postoperatively, infective endocarditis, bypass time, cardiogenic shock, non-RBC blood products transfused peri- or postoperatively, gender, reoperation for bleeding, age, estimated glomerular filtration rate, urgency status, hypercholesterolemia, hypertension, cardiac surgery procedure type, and respiratory disease (Table 4).
All these risk factors were significant in $70 \%$ or more of the bootstrap samples. For this final postoperative model, the performance in the validation data set was as follows: AUC $=0.81$, indicating good discrimination ability, and HL- $P=.6$, indicating acceptable calibration.

Using the point scores in Table 4, the total patient scores ranged from 4 to 57 . The mean predicted risk for the groups defined by the point ranges of 4 to 15 points, 16 to 25 points, 26 to 35 points, and 36 to 57 was $1 \%, 3 \%, 9 \%$, and $30 \%$, respectively (information available online in Table E1).

The 2 models were fitted to the subset of data $(n=2679)$ that had been used to measure the performance of the 3 published models, and an AUC of 0.77 and 0.83 was found for the preoperative and postoperative models, respectively.

The comparison of performance of our models and the 3 published models in the validation data set showed that the results did not depend on exactly what subset of data the 
TABLE 3. Patient characteristics and preoperative risk factors in a prediction model for postoperative AKI among patients undergoing cardiac surgery

\begin{tabular}{|c|c|c|c|c|}
\hline Risk factor & $\begin{array}{l}\text { Regression } \\
\text { coefficient* }\end{array}$ & $\begin{array}{l}\text { Point } \\
\text { score } \dagger\end{array}$ & OR & $P$ value \\
\hline Obesity $\left(\right.$ BMI $>30 \mathrm{~kg} / \mathrm{m}^{2}$ ) & 0.376 & 2 & 1.45 & $<.001$ \\
\hline Infective endocarditis & 0.987 & 6 & 2.68 & $<.001$ \\
\hline \multicolumn{5}{|c|}{$\begin{array}{l}\text { Cardiac surgery procedure type } \\
\text { (isolated CABG, reference } \\
\text { group) }\end{array}$} \\
\hline Valves only & 0.471 & 3 & 1.60 & $<.001$ \\
\hline Valves and CABG & 0.668 & 4 & 1.95 & $<.001$ \\
\hline Other $\ddagger$ & 1.005 & 6 & 2.73 & $<.001$ \\
\hline \multicolumn{5}{|c|}{$\begin{array}{l}\text { Preoperative serum creatinine } \\
\text { level }(\mu \mathrm{mol} / \mathrm{L} ;<70, \\
\text { reference group })\end{array}$} \\
\hline $70-100$ & 0.511 & 3 & 1.67 & $<.001$ \\
\hline $101-120$ & 0.899 & 5 & 2.46 & $<.001$ \\
\hline $121-150$ & 1.280 & 8 & 3.60 & $<.001$ \\
\hline$>150$ & 1.436 & 9 & 4.20 & $<.001$ \\
\hline Diabetes & 0.392 & 2 & 1.48 & $<.001$ \\
\hline \multicolumn{5}{|l|}{$\begin{array}{l}\text { Urgency status (elective, } \\
\text { reference group) }\end{array}$} \\
\hline Urgent & 0.168 & 1 & 1.18 & .005 \\
\hline Emergency & 0.959 & 6 & 2.61 & $<.001$ \\
\hline Salvage & 1.292 & 8 & 3.64 & $<.001$ \\
\hline \multicolumn{5}{|c|}{$\begin{array}{l}\text { eGFR }\left(\mathrm{mL} / \mathrm{min} / 1.73 \mathrm{~m}^{2} ; \geq 90,\right. \\
\text { reference group }) \S\end{array}$} \\
\hline $60-90$ & 0.207 & 1 & 1.23 & .02 \\
\hline $30-60$ & 0.534 & 3 & 1.71 & $<.001$ \\
\hline$<30$ & 0.531 & 3 & 1.70 & .001 \\
\hline Congestive heart failure & 0.386 & 2 & 1.47 & $<.001$ \\
\hline Age (per 10 y) & 0.167 & 1 & 1.18 & $<.001$ \\
\hline Cardiogenic shock & 0.700 & 4 & 2.01 & $<.001$ \\
\hline
\end{tabular}

$O R$, Odds ratio; $A K I$, acute kidney injury; $B M I$, body mass index; $C A B G$, isolated cor onary artery bypass grafting; $e G F R$, estimated glomerular filtration rate. ${ }^{*}$ The intercept of the multivariate model was -5.865 . $\nmid$ The point score was obtained by a linear transformation of the regression coefficients; the regression coefficient of each risk factor was divided by the absolute value of the age coefficient, with the result rounded to the nearest integer. ${ }^{18} \ddagger$ Included aortic procedure, atrial arrhythmia surgery, correction of atrial septal defect, cardiac transplantation, left ventricular aneurysm, cardiac tumor, pericardiectomy, left ventricular outflow tract myectomy for left ventricular outflow tract, correction of acquired ventricular septal defect, left ventricular reconstruction, cardiac trauma, left ventricle rupture repair, pulmonary thromboendarterectomy, other cardiac surgery, other noncardiac surgery, other congenital complications. §eGFR calculated using the Cockroft-Gault formula: for men: weight $(\mathrm{kg}) \times(140-$ age $[\mathrm{y}]) /(72 \times$ serum creatinine $[\mathrm{mg} / \mathrm{dL}])$; for women: weight $(\mathrm{kg}) \times(140-$ age $[\mathrm{y}]) \times 0.85 /(72 \times$ serum creatinine $[\mathrm{mg} / \mathrm{dL}])$.

analysis was restricted to and how exactly the risk factors were defined.

\section{DISCUSSION}

As more and more patients undergo cardiac surgery, and these patients become older and have more comorbidities, AKI has been increasing as a common postoperative complication. The focus of some studies has been on the management and prognosis of these patients. These patients often require early and intensive dialysis therapy and have had a high mortality rate, ${ }^{19}$ as illustrated by the 10 -fold increase in crude mortality seen in our population.

Because more studies have been called for to develop and validate scores to predict milder AKI than solely as defined by the need for RRT after cardiac surgery, ${ }^{11}$ our aim was to identify the best combination of pre-, peri-, and early postoperative risk factors for AKI, defined as need for RRT or both a doubling of the serum creatinine from the preoperative level and a postoperative creatinine reaching a level greater than $200 \mu \mathrm{mol} / \mathrm{L}(2.26 \mathrm{mg} / \mathrm{dL})$. Furthermore, the present study is one of the largest published series of patients, included all groups undergoing cardiac surgery, and is the first study investigating the risk factors for developing AKI after cardiac surgery in Australian patients. The present results have concurred with some of the previous reports showing that the incidence of AKI increases with patient-related risk factors such as diabetes and obesity and procedure-related risk factors such as RBC transfusion. $2,3,7,20$

Although the requirement for RRT has been recognized as a serious complication, mild impairment of renal function is often regarded as a "benign" event. However, it has been found that even a minimal increase in the serum creatinine postoperatively is associated with a nearly threefold increase in 30-day mortality, with a larger elevation of $0.5 \mathrm{mg} / \mathrm{dL}$ ( $44 \mu \mathrm{mol} / \mathrm{L})$ or more associated with more than 18-fold increase in 30-day mortality. ${ }^{21}$ A more recent study $^{20}$ that analyzed the relationship among 3 thresholds of AKI $(>25 \%,>50 \%$, and $>75 \%$ decrease in the estimated glomerular filtration rate) and 7-day postoperative mortality, found 4-, 7-, and 10-fold increases in the odds of death, respectively.

Using multivariate analysis of the putative risk factors for the development of AKI after cardiac surgery, we have identified greater preoperative serum creatinine levels as a strong factor. These results are in accordance with those previously reported by others, ${ }^{6}$ in which an elevated preoperative serum creatinine has consistently been shown to be a significant independent risk factor for the development of AKI. ${ }^{1-4,6-10,20,21}$

The effects of IABP use and the use of RBCs contributing to renal dysfunction have been controversial. Our study adds to the evidence that IABP use, the use of RBCs, and non-RBC transfusion as early postoperative risk factors could be detrimental in developing $\mathrm{AKI}^{3,4,7,20}$ These variables are considered as markers of poor hemodynamic and renal perfusion status, which could be causative factors. ${ }^{4}$ Theoretically, the use of RBCs should increase tissue oxygenation and thus improve kidney function. However, studies with conflicting results have been published regarding the efficacy of using RBCs that have been stored for a period, because evidence has shown that the quality of the RBCs can deteriorate with storage, leading to morphologic changes that can impair tissue oxygen delivery. ${ }^{7,22}$ 
TABLE 4. Patient characteristics and pre-, peri-, and early postoperative risk factors in a prediction model for postoperative AKI among patients undergoing cardiac surgery

\begin{tabular}{|c|c|c|c|c|}
\hline Risk factor & Regression coefficients* & Point scores $\dagger$ & OR & $P$ value \\
\hline Obesity $\left(\right.$ BMI $>30 \mathrm{~kg} / \mathrm{m}^{2}$ ) & 0.518 & 4 & 1.68 & $<.001$ \\
\hline \multicolumn{5}{|c|}{ Preoperative serum creatinine level ( $\mu \mathrm{mol} / \mathrm{L} ;<70$, reference group) } \\
\hline $70-100$ & 0.545 & 4 & 1.72 & $<.001$ \\
\hline $101-120$ & 0.860 & 6 & 2.36 & $<.001$ \\
\hline $121-150$ & 1.232 & 9 & 3.43 & $<.001$ \\
\hline$>150$ & 1.312 & 9 & 3.71 & $<.001$ \\
\hline Diabetes & 0.386 & 3 & 1.47 & $<.001$ \\
\hline \multicolumn{5}{|l|}{ IABP use (no IABP, reference group) } \\
\hline IABP use preoperatively & 0.293 & 2 & 1.34 & .02 \\
\hline IABP use peri- or postoperatively & 1.089 & 8 & 2.97 & $<.001$ \\
\hline Infective endocarditis & 0.811 & 6 & 2.25 & $<.001$ \\
\hline Bypass time $>180 \mathrm{~min}$ & 0.484 & 3 & 1.62 & $<.001$ \\
\hline Cardiogenic shock & 0.587 & 4 & 1.80 & $<.001$ \\
\hline Non-RBC products transfused & 0.345 & 2 & 1.41 & $<.001$ \\
\hline Gender & 0.204 & 1 & 1.23 & .004 \\
\hline \multicolumn{5}{|c|}{$\begin{array}{l}\text { RBCs transfused intra- and/or postoperatively (operative reintervention required } \\
\text { for bleeding/tamponade; no RBC and no reoperation, reference group) }\end{array}$} \\
\hline $\mathrm{RBC}$ and no reoperation & 0.936 & 7 & 2.55 & $<.001$ \\
\hline Reoperation & 1.535 & 11 & 4.64 & $<.001$ \\
\hline Age (per 10 y) & 0.139 & 1 & 1.15 & $<.001$ \\
\hline \multicolumn{5}{|l|}{ eGFR $\left(\mathrm{mL} / \mathrm{min} / 1.73 \mathrm{~m}^{2} ; \geq 90\right.$, reference group $) \ddagger$} \\
\hline $60-90$ & 0.560 & 2 & 1.75 & .003 \\
\hline $30-60$ & 0.483 & 3 & 1.62 & $<.001$ \\
\hline$<30$ & 0.168 & 1 & 1.18 & .1 \\
\hline \multicolumn{5}{|l|}{ Urgency status (elective, reference group) } \\
\hline Urgent & 0.014 & 0 & 1.01 & .8 \\
\hline Emergency & 0.555 & 4 & 1.74 & $<.001$ \\
\hline Salvage & 0.701 & 5 & 2.02 & .007 \\
\hline Hypercholesterolemia & -0.184 & -1 & 0.83 & .004 \\
\hline Hypertension & 0.227 & 2 & 1.25 & .001 \\
\hline \multicolumn{5}{|c|}{ Cardiac surgery procedure type (isolated CABG, reference group) } \\
\hline Valves only & 0.451 & 3 & 1.57 & $<.001$ \\
\hline Valves and $\mathrm{CABG}$ & 0.320 & 2 & 1.38 & $<.001$ \\
\hline Other§ & 0.700 & 5 & 2.01 & $<.001$ \\
\hline Respiratory disease & 0.265 & 2 & 1.30 & $<.001$ \\
\hline
\end{tabular}

$A K I$, Acute kidney injury; $B M I$, body mass index; $C A B G$, isolated coronary artery bypass grafting; $e G F R$, estimated glomerular filtration rate; $I A B P$, intra-aortic balloon pump; $R B C$, red blood cell; $O R$, odds ratio. *The intercept of the multivariate model was -6.467 . $\dagger$ The point score was obtained by a linear transformation of the regression coefficients; the beta coefficient of each risk factor was divided by the absolute value of the age coefficient, with the result rounded to the nearest integer. ${ }^{18} \ddagger$ Included aortic procedure, atrial arrhythmia surgery, correction of atrial septal defect, cardiac transplantation, left ventricular aneurysm, cardiac tumor, pericardiectomy, left ventricular outflow tract myectomy for left ventricular outflow tract, correction of acquired ventricular septal defect, left ventricular reconstruction, cardiac trauma, left ventricle rupture repair, pulmonary thromboendarterectomy, other cardiac surgery, other noncardiac surgery, other congenital complications. §eGFR calculated using the Cockroft-Gault formula: for men: weight $(\mathrm{kg}) \times(140-$ age $[\mathrm{y}]) /(72 \times$ serum creatinine $[\mathrm{mg} / \mathrm{dL}])$; for women: weight $(\mathrm{kg}) \times(140-$ age $[\mathrm{y}]) \times 0.85 /(72 \times$ serum creatinine $[\mathrm{mg} / \mathrm{dL}])$.

It is worthwhile to note that in patients undergoing coronary artery bypass grafting and/or valve procedures, our study showed infective endocarditis to be a significant risk factor. To our knowledge, this has only been previously described by Provenchere et al, ${ }^{9}$ although some other studies have identified it as a risk factor in patients undergoing coronary surgery. A number of mechanisms for renal dysfunction have been suggested in this group of patients, including immune complex-mediated glomerulonephritis, nephrotoxicity from antibiotic regimens, renal artery embolism, and hemodynamic disturbance. ${ }^{23,24}$
Few studies have included obesity or an increased body mass index in their analyses. Of those that did, Chertow et $\mathrm{al}^{25}$ concluded that obesity was unrelated to the risk of developing AKI, and Van Straten et $\mathrm{al}^{7}$ found that patients with a body mass index greater than $35 \mathrm{~kg} / \mathrm{m}^{2}$ might have increased risk. Billings et $\mathrm{al}^{26}$ provided a more recent and targeted study and found that obesity independently predicts AKI after cardiac surgery, which our results support. The exact mechanism and effect of obesity on postoperative AKI is not clear; however, increased oxidative stress from obesity has been suggested. ${ }^{26}$ 
An existing 10-variable preoperative model for AKI requiring dialysis after open heart surgery ${ }^{13}$ includes gender, history of congestive heart failure, severe left ventricular dysfunction (ejection fraction $<35 \%$ ), preoperative use of IABP, history of chronic obstructive pulmonary disease requiring medical therapy, diabetes mellitus, previous open heart surgery, emergency surgery, type of cardiac surgery, and preoperative serum creatinine. That model's performance decreased from an AUC of 0.82 at development to an AUC of 0.75 for the ANZSCTS patients.

In a 7-variable preoperative model for RRT after cardiac surgery, ${ }^{15}$ the preoperative estimated glomerular filtration rate, diabetes mellitus requiring medication, left ventricular ejection fraction, previous cardiac surgery, procedure, urgency of surgery, and preoperative IABP use combined to give an AUC of 0.76 at development and 0.75 for the ANZSCTS patients.

Another 10-variable preoperative model ${ }^{14}$ to predict the need for postoperative dialysis after undergoing coronary artery bypass grafting and/or valve surgery performed relatively poorly for the ANZSCTS patients, although the exclusion of NYHA class could explain that.

Two of these existing risk prediction tools for AKI requiring dialysis have 10 risk factors, the same size as our preoperative model for a milder definition of AKI, but all suggestive of the need to consider quite a broad mix of risk factors for accurate prediction in this context. Our preoperative model for AKI had better discrimination ability than the existing models for RRT, although the comparisons were hampered by missing data. The addition of peri- and early postoperative information substantially improved the predictive ability.

\section{Strengths and Limitations}

Some limitations should be considered for this prediction modeling. First, the possibility remains that unmeasured factors could have affected the outcome. For example, proteinuria, which reflects structural damage to the glomeruli or renal tubules, has been shown to be an independent risk factor for the development of cardiac surgeryassociated AKI but was unavailable to us. ${ }^{27}$ Future studies on cost-effective methods to screen patients before surgery are needed. Other potentially important variables include perioperative management variables such as drugs, transfusions, and urine output. ${ }^{5}$ Second, 2 variables, the patient's NYHA class and the number of RBC units used during surgery, were excluded because of missing data. Furthermore, the characteristics of the hospitals at which the patients were treated were not considered, because their inclusion would have potentially restricted future applications and generalization of the developed model. Finally, although these risk prediction models performed reasonably well in this Australian population, external validation is required in other populations.
Our study had notable strengths. This was a cohort study involving 18 hospitals and more than 28,000 cardiac surgeries. Compared with other studies of AKI, defined as need for RRT, a definition of milder AKI was used in the present study. We analyzed the data from patients who had undergone all types of cardiac surgery, including coronary artery bypass grafting and valve surgery.

\section{CONCLUSIONS}

Our study of more than 28,000 patients during an 8-year period identified 2 separate models, 1 including the preoperative risk factors and the other including the pre-, peri-, and early postoperative risk factors, to predict postoperative AKI after Australian cardiac surgery. These models had good discrimination and acceptable calibration on internal validation. These risk prediction models could be useful in identifying patients who are at high risk of postoperative AKI and enable optimization of the pre-, peri-, and early postoperative care. Additionally, the preoperative model could be useful to identify suitable patients for clinical trials of novel interventions to prevent AKI after cardiac surgery, and the postoperative model could be useful for guiding intensive care and for retrospective performance audits of care of cardiac surgery patients.

We thank the following staff of the ANZSCTS Data Management Centre, Monash University for practical assistance: Dr Lavinia Tran, Dr Diem Dinh, and Ms Angela Brennan. We acknowledge the essential role of the members of the Australasian Society of Cardiac and Thoracic Surgeons Database Program Steering Committee in the ongoing existence of the registry and facilitating its use for our project: Mr Gil Shardey (Chair), Mr Peter Skillington, Mr Julian Smith, Mr Andrew Newcomb, Mr Siven Seevanayagam, Mr Bo Zhang, Mr Hugh Wolfenden, Mr Adrian Pick, Professor Chris Reid, Dr Lavinia Tran, Dr Diem Dinh, and Mr Andrew Clarke. The following investigators, data managers, and institutions participated in the Australasian Society of Cardiac and Thoracic Surgeons database: Alfred Hospital, Pick A, Duncan J; Austin Hospital, Seevanayagam S, Shaw M; Cabrini Health, Shardey G; Geelong Hospital, Morteza M, Zhang B, Bright C; Flinders Medical Centre, Knight J, Baker R, Helm J, Canning N; Jessie McPherson Private Hospital, Smith J, Baxter H; John Hunter Hospital, James A, Scaybrook S; Lake Macquarie Hospital, Dennett B, Mills M; Liverpool Hospital, French B, Hewitt N; Mater Health Services, Diqer AM, Curtis L; Monash Medical Centre, Smith J, Baxter H; Prince of Wales Hospital, Wolfenden H, Weerasinge D; Royal Melbourne Hospital, Skillington P, Law S; Royal Prince Alfred Hospital, Wilson M, Turner L; St George Hospital, Fermanis G, Newbon P; St Vincent's Hospital, VIC, Yii M, Newcomb A, Mack J, Duve K; St Vincent's Hospital, NSW, Spratt P, Hunter T; The Canberra Hospital, Bissaker P, Bhosale M; Townsville Hospital, Tam R, Farley A; Westmead Hospital, Costa R, Halaka M.

\section{References}

1. Chertow GM, Burdick E, Honour M, Bonventre JV, Bates DW. Acute kidney injury, mortality, length of stay, and costs in hospitalized patients. J Am Soc Nephrol. 2005;16:3365-70. 
2. Rosner MH, Okusa MD. Acute kidney injury associated with cardiac surgery. Clin J Am Soc Nephrol. 2006;1:19-32.

3. Conlon PJ, Stafford-Smith M, White WD, Newman MF, King S, Winn MP, et al. Acute renal failure following cardiac surgery. Nephrol Dialysis Transplant. 1999; 14:1158-62.

4. Zanardo G, Michielon P, Paccagnella A, Rosi P, Caló M, Salandin V, et al. Acute renal failure in the patient undergoing cardiac operation: prevalence, mortality rate, and main risk factors. J Thorac Cardiovasc Surg. 1994;107:1489-95.

5. Parolari A, Pesce LL, Pacini D, Mazzanti V, Salis S, Sciacovelli C, et al. Risk factors for perioperative acute kidney injury after adult cardiac surgery: role of perioperative management. Ann Thorac Surg. 2012;93:584-91.

6. Antunes PE, Prieto D, Ferraõ de Oliveira J, Antunes MJ. Renal dysfunction after myocardial revascularization. Eur J Cardiothoracic Surg. 2004;25:597-604.

7. Van Straten AH, Hamad MA, Van Zundert AA, Martens EJ, Schönberger JP, de Wolf AM. Risk factors for deterioration of renal function after coronary artery bypass grafting. Eur J Cardiothoracic Surg. 2010;30:106-11.

8. Anandh U, Rajkumar J, Shetty D. Acute renal failure following cardiac surgery: factors predicting mortality and short term renal prognosis. Indian J Nephrol. 2005;15(Suppl 2):S7-9.

9. Provenchere S, Plantefeve G, Hufnagel G, Vicaut E, De Vaumas C, Lecharny JB, et al. Renal dysfunction after cardiac surgery with normothermic cardiopulmonary bypass: incidence, risk factors and effect on clinical outcome. Anesth Analg. 2003;96:1258-64.

10. Ryckwaert F, Boccara G, Frappier JM, Colson PH. Incidence, risk factors, and prognosis of a moderate increase in plasma creatinine early after cardiac surgery. Crit Care Med. 2002;30:1495-8.

11. Huen SC, Parikh CR. Predicting acute kidney injury after cardiac surgery: a systematic review. Ann Thorac Surg. 2012;93:337-47.

12. Reid CM, Rockell M, Skillington PD, Shardey GC, Smith JA, Yii M, et al. Initial twelve months experience and analysis for 2001-2002 from the Australasian Society of Cardiac and Thoracic Surgeons-Victorian database project. Heart Lung Circ. 2004;13:291-7.

13. Thakar CV, Arrigain S, Worley S, Yared JP, Paganini EP. A clinical score to predict acute renal failure after cardiac surgery. J Am Soc Nephrol. 2005;16:162-8.

14. Mehta RH, Grab JD, O'Brien SM, Bridges CR, Gammie JS, Haan CK, et al. Bedside tool for predicting the risk of postoperative dialysis in patients undergoing cardiac surgery. Circulation. 2006;114:2208-16.
15. Wijeysundera DN, Karkouti K, Dupuis JY, Rao V, Chan CT, Granton JT, et al Derivation and validation of a simplified predictive index for renal replacement therapy after cardiac surgery. JAMA. 2007;297:1801-9.

16. Efron B, Tibshirani RJ. Estimates of bias. In: Cox DR, Hinkley DV, Reid N Rubin DB, Silverman BW, eds. An Introduction to the Bootstrap. New York: Chapman \& Hall; 1993:124-40.

17. Steyerberg EW. Clinical Prediction Models: A Practical Approach to Development, Validation, and Updating. New York: Springer; 2009.

18. Rassi JA, Rassi A, Little WC, Xavier R, Rassi SG, Rassi AG, et al. Development and validation of a risk score for predicting death in Chagas' heart disease. $N$ Engl J Med. 2006;355:799-808.

19. Thakar CV, Worley S, Arrigain S, Yared JP, Paganini EP. Influence of renal dysfunction on mortality after cardiac surgery: modifying effect of preoperative renal function. Kidney Int. 2005;67:1112-9.

20. Karkouti K, Wijeysundera DN, Yau TM, Callum JL, Cheng DC, Crowther M, et al. Acute kidney injury after cardiac surgery: focus on modifiable risk factors. Circulation. 2009;119:495-502.

21. Lassnigg A, Schmidlin D, Mouhieddine M, Bachmann LM, Druml W, Bauer P, et al. Minimal changes of serum creatinine predict prognosis in patients after cardiothoracic surgery: a prospective cohort study. J Am Soc Nephrol. 2004;15: 1597-605.

22. Yap CH, Lau L, Krishnaswamy M, Gaskell M, Yii M. Age of transfused red cells and early outcomes after cardiac surgery. Ann Thorac Surg. 2008;86:554-9.

23. Conlon PJ, Jefferies F, Krigman HR, Corey GR, Sexton DJ, Abramson MA. Predictors of prognosis and risk of acute renal failure in bacterial endocarditis. Clin Nephrol. 1998;49:96-101.

24. Majumdar A, Chowdhary S, Ferreira MAS, Hammond LA, Howie AJ, Lipkin GW, et al. Renal pathological findings in infective endocarditis. Nephrol Dial Transplant. 2000;15:1782-7.

25. Chertow GM, Lazarus JM, Christiansen CL, Cook EF, Hammermeister KE Grover F, et al. Preoperative renal risk stratification. Circulation. 1997;95:878-84.

26. Billings FT, Pretorius M, Schildcrout JS, Mercaldo ND, Byrne JG, Ikizler TA, et al. Obesity and oxidative stress predict AKI after cardiac surgery. J Am Soc Nephrol. 2012;23:1221-8.

27. Coca SG, Jammalamadaka D, Sint K, Philbrook HT, Shlipak MG, Zappitelli M, et al. Preoperative proteinuria predicts acute kidney injury in patients undergoing cardiac surgery. J Thorac Cardiovasc Surg. 2012;143:495-502. 
TABLE E1. Mean and range of predicted AKI probabilities in different risk score categories using validation data set

\begin{tabular}{lccc}
\hline & Patients $(\%)$ & Mean & Range \\
\hline Preoperative model & & & \\
$\quad$ Risk score $<15$ & 43 & 0.02 & $0.01-0.06$ \\
Risk score $\geq 15$ to $<25$ & 52 & 0.07 & $0.02-0.26$ \\
$\quad$ Risk score $\geq 25$ & 5 & 0.25 & $0.07-0.71$ \\
Postoperative model & & & \\
$\quad$ Risk score $<15$ & 19 & 0.01 & $0.003-0.02$ \\
Risk score $\geq 15$ to $<25$ & 47 & 0.03 & $0.01-0.09$ \\
Risk score $\geq 25$ to $<35$ & 27 & 0.09 & $0.03-0.29$ \\
Risk score $\geq 35$ & 7 & 0.30 & $0.12-0.85$ \\
\hline
\end{tabular}

$A K I$, Acute kidney injury. 